\title{
Beyond the Prevention of Harm: Animal Disease Policy as a Moral Question
}

\author{
Franck L. B. Meijboom • Nina Cohen • \\ Elsbeth N. Stassen · Frans W. A. Brom
}

Accepted: 14 April 2009/Published online: 28 May 2009

(C) The Author(s) 2009. This article is published with open access at Springerlink.com

\begin{abstract}
European animal disease policy seems to find its justification in a "harm to other" principle. Limiting the freedom of animal keepers-e.g., by culling their animals-is justified by the aim to prevent harm, i.e., the spreading of the disease. The picture, however, is more complicated. Both during the control of outbreaks and in the prevention of notifiable, animal diseases the government is confronted with conflicting claims of stakeholders who anticipate running a risk to be harmed by each other, and who ask for government intervention. In this paper, we first argue that in a policy that aims to prevent animal diseases, the focus shifts from limiting "harm" to weighing conflicting claims with respect to "risks of harm." Therefore, we claim that the harm principle is no longer a sufficient justification for governmental intervention in animal disease prevention. A policy that has to deal with and distribute conflicting risks of harm needs additional value assumptions that guide this process of assessment and distribution. We show that currently, policies are based on assumptions that are mainly economic considerations. In order to show the limitations of these considerations, we use the interests and position of keepers of backyard animals as an example. Based on the problems they faced during and after the recent outbreaks, we defend the thesis that in order to develop a sustainable animal disease policy other than economic assumptions need to be taken into account.
\end{abstract}

F. L. B. Meijboom $(\square)$. F. W. A. Brom

Animal Breeding and Genomics Centre, Wageningen University, Wageningen, The Netherlands

e-mail: F.L.B.Meijboom@uu.nl

N. Cohen · E. N. Stassen

Animals and Society, Animal Production Systems Group, WIAS, Wageningen University,

Wageningen, The Netherlands

F. L. B. Meijboom

Ethics Institute, Utrecht University, Heidelberglaan 8, NL-3584 Utrecht, The Netherlands 
Keywords Animal disease control · Harm principle ·

Keepers of backyard animals · Risk - Moral values

\section{Introduction}

As in many parts of Europe, The Netherlands have been confronted with several outbreaks of notifiable animal diseases ${ }^{1}$ : classical swine fever in 1997-1998, foot and mouth disease in 2001, and avian influenza (bird flu) in 2003. The disease control policy of The Netherlands was in line with the stringent EU regulations for the control of notifiable animal diseases at that time: a non-vaccination policy, ${ }^{2}$ and in case of an outbreak, a stamping-out strategy. Animals that are either infected, possibly infected or are a potential carrier of the disease, are culled in order to prevent further spread of the disease. This strategy has raised a lot of public concerns with a clear moral dimension. Questions as whether the control of notifiable animal diseases justifies the killing of large numbers of animals, and whether there are alternatives available for mass culling has been on the public agenda ever since (cf. Cohen et al. 2007)

These questions can be addressed from different perspectives, such as the animal, the perspective of food safety and public health, or the animal keeper. In this article, we focus on one specific stakeholder: the keeper of backyard animals. Keepers of backyard animals are a diverse, but substantial group in The Netherlands. An estimated 400,000 citizens keep a few million animals and spend at least a few billion euros on their hobby each year (Van Velzen and Dekker 2003; Treep et al. 2004; den Boer et al. 2004; Sijtsema et al. 2005). Their position is between the professional animal keeper and the keeper of pets. On the one hand, backyard animals are commonly not kept for commercial purposes. On the other hand and in contrast to pet animals, these animals are not kept in the house. In a quantitative study, performed as part of our research project, the main reasons for keeping backyard animals are human-animal contact and breeding of fancy or rare breeds rather than commercial purposes. They consider keeping animals as a way of living. It is a hobby that is an intrinsic part of their life. This group of animal keepers appears to be extremely critical in their assessment of the policy during the last outbreaks. They argue that their interests and values are not taken seriously ( $c f$. Beekman et al. 2007).

In this article, we analyze the background and the implications of this criticism on the animal disease policy. ${ }^{3}$ After having presented the harm principle as the obvious justification that underlies recent policy measures, the shortcomings of this principle in the context of animal disease prevention is discussed (see "The Harm Principle as

\footnotetext{
1 A notifiable animal disease is one that must be immediately reported to the authorities and includes all animal diseases subject to national and/or international regulations.

2 In the subsequent years after the epidemics the Dutch government initiated a debate at the European level to re-evaluate the non-vaccination policy. As a result vaccination-to-live is since 2006 allowed for foot and mouth disease and avian influenza based on the EC directive 2006/14/EC.

3 The articles in the Special Issue of the Journal of Agricultural and Environmental Ethics on animal diseases (vol $17 \mathrm{nr} .4-5,2004)$ provide an interesting and helpful context for our discussion.
} 
a Problematic Justification of Animal Disease Policy"). Rather than the prevention of harm, the problematic aspect in animal disease prevention is the question how we should weigh the conflicting "risks of harm" claims. With respect to conflicting "risks of harm," the harm principle is silent on how to weigh competing claims of "risks of harm." Therefore, governmental policy needs additional arguments in order to weigh and prioritize different "risks of harm" (see "Risks, Conflicts, and the Silence of the Harm Principle"). The fact that governments all over Europe are able to deal with diverging and sometimes conflicting "risks of harm" claims shows that, next to the harm principle, additional assumptions are included in the policy and legislation. Currently, these assumptions are veterinary and economic in nature. Consequently, problems of animal disease prevention are addressed as mainly veterinary and economic problems. The criticism of the keepers of backyard animals is a clear indication of the shortcomings of this scope (Section The Criticism of Keepers of Backyard Animals). Keepers of backyard animals do not feel wronged in economic terms, but feel wronged in moral terms. They believe the infringement of their lifestyle is justified on grounds with which they do not agree. Thus, what is presented as a veterinary and economic problem turns out to be a question with a clear moral dimension. Ignoring this moral dimension can only be at the cost of leaving the values and interests of some groups out of consideration without sufficient justification (Section The Central Role of Value Assumptions and the Problem of an "Economy Only" Ciew).

\section{The Harm Principle as a Problematic Justification of Animal Disease Policy}

The current animal disease policy often has a serious impact on both animals and animal keepers, such as the culling of animals and the restrictions of transportation. This directly intervenes in the freedom of the individual animal keeper. Nonetheless, these measures are considered to be justified in that they aim to prevent society from further harm, i.e., the spreading of the disease and the subsequent consequences for food production, transport, and trade.

This justification seems to be based on the "harm to others" principle. The most basic interpretation of the harm principle, as was introduced by Mill (1859/1979) and further developed by many other authors (cf. Hart 1961; Feinberg 1984, 1994), roughly states that governmental intervention is justified when it is aimed to prevent harm to others. The principle starts from the ideal that every individual enjoys maximum freedom that is still consistent with equal liberties of his fellow citizens. Therefore, it is only justified to restrict the liberty of person $A$ in order to prevent that person from causing harm to person $B$, who can be a specific person, but also a member of the public in general. Harming is in this context defined as a wrongful setback of interests (Feinberg 1994, p. 4, 34). However, harm as such is not a sufficient condition for evaluating the situation as morally impermissible. If it were a sufficient condition, the moral claim that we ought not to impose harm on others would have serious implications. In a very strict version the claim would imply that broadly accepted practices, such as driving your car is problematic, because it certainly is related to harm for many others. At this point, two additional elements 
are relevant: intentionality, and care. The harm principle is about harm that is deliberately and intentionally imposed on others or that is the result of obvious carelessness or negligence. The harm principle can justify strong interventions in the freedom of, for instance, an animal keeper, who deliberately tries to harm others by contributing to the spread of a disease. Furthermore, the harm principle can be applied, if one is confronted with negligence. For example, it is assumed that the outbreak of classical swine fever in The Netherlands in 1997 has been caused by a lorry-driver that used to transport pigs in a region of Germany in which the virus for classical swine fever was detected. His truck was not properly disinfected and as a result millions of pigs had to be killed as part of the attempt to bring the disease under control (Stegeman et al. 2000, p. 186). Although, the outbreak was not the result of a deliberate choice to harm others, the involved person obviously has made serious mistakes for which he can be accused.

However, in practice, only but very few agents in the animal sector really intend to harm others. Furthermore, outbreaks also occur even if there is not a situation of negligence. Out of perfectly decent, prima facie plausible motives some acts can impose a serious risk of an outbreak. For instance, feeding cows with commercial feed that contains bones and brains from animals was not done out of cruelty towards the animals or with the intention to endanger animal health. Nonetheless, it has been directly related to the outbreak of mad cow disease in the UK in the 1990s. This illustrates that, in the practice of animal disease policy, a justification of the government intervention by reference to the harm principle only is less straightforward. Only part of all current government interventions can be sufficiently justified by this principle.

In answer to this, it can be argued that the harm principle can also be interpreted in a less restricted way. Brink (2007), for instance, shows that the harm principle also can be interpreted as: "A can restrict B's liberty in order to prevent harm to others" He distinguishes this, so-called $\mathrm{HP}_{2}$-version from the more restricted $\mathrm{HP}_{1^{-}}$ version that states that: "A can restrict B's liberty to prevent $B$ from harming others." It is clear that $\mathrm{HP}_{1}$ only justifies intervention if "the target herself would be the cause of harm to others." $\mathrm{HP}_{2}$ also allows intervention in order to prevent harm to others, "whether that harm would be caused by the target or in some other way." In this case B need not intend to harm or even to be fully aware of the harm that may result from his actions. This last version seems to be more in line with what is at stake in animal disease policy. Reasons for intervention are not restricted to the fact that animal keepers directly harm others, but government intervenes because their actions may impose harm on others. It is a risk of harm. The BSE feed restrictions, which were designed to reduce the spread of BSE, are a good example. The so-called ruminant-to-ruminant feed ban implies the prohibition of the feeding of ruminant animals, e.g., cattle, sheep, and goats, with animal proteins of mammalian origin. The introduction of this prohibition entails an intervention in the freedom of several actors in the animal food sector. Nevertheless, it is considered to be an issue that has to be subject of governmental law and policy not because these actors directly harm others if they feed their animals with animal proteins of mammalian origin, but because it involves a risk of harm if animals that are herbivores by nature are fed with feed from animal origin. Therefore, from the less restrictive interpretation of 
the harm principle, the government is allowed to introduce such compulsory measures.

However, even this less restrictive interpretation of the harm principle is not sufficient to justify all measures that are part of animal disease policy. Governments often are confronted with a web of different, overlapping, but also conflicting claims of harm, rather than with a clear distinction between the harmers and those who are harmed. The tension between commercial actors in the livestock sector and keepers of backyard animals can highlight this point. Both groups do not aim to harm each other and they sincerely aim to prevent an outbreak of an animal disease. Nonetheless, they differ with respect to the view on what risks of harm are acceptable. For instance, commercial keepers may consider the presence of actors who keep animals for reasons of hobby as a risk factor, because they are less organized and operate in a less standardized way and thus the traceability of possibly infected animals is low. Consequently, this way of animal keeping may jeopardize the business security of the commercial animal keeper. On the other hand, keepers of backyard animals do not consider this assumed risk of harm for the commercial sector a sufficient justification for a restriction in their freedom of lifestyle. They are convinced that their animals are not the cause of disease outbreaks, and do not contribute to a further spread of the disease. A recent study on the avian influenza virus in The Netherlands in 2003 substantiates their conviction (Bavinck et al. 2009). They even may claim that these commercial keepers and their focus on trade and export are a risk to their idea of the good life and their way of caring for their animals.

In such cases, the problem is not that one partner will be harmed by another if the government does not intervene, but that both partners anticipate running a risk to be harmed by each other, and ask for government intervention. In order to deal with such problems, the government needs tools to weigh and assess conflicting claims of harm and to cope with the risk element of harm. These are tools that the harm principle cannot provide.

\section{Risks, Conflicts, and the Silence of the Harm Principle}

Given the fact that European governments are confronted with conflicting claims of stakeholders who anticipate running a risk to be harmed by each other, and who ask for government intervention, a justification of government intervention based on the harm principle only becomes complicated. The conflicting claims and the aspect of risk complicate the government's decision to choose the option that preserves the most freedom.

First, the conflicting claims of stakeholders illustrate that governments have to deal with various kinds and amounts of harm. Confronted with conflicts of legitimate claims, the government has a serious priority problem. They have to compare and evaluate the different claims in order to be able to intervene and prevent. This implies a process of assessing "the types of harm, the amounts of harm, and our willingness, as a society, to bear the harms." (Harcourt 1999, p. 182) In this process the harm principle does not provide much guidance. Even stronger, 
"the harm principle is silent on those questions." (Harcourt 1999, p. 182) The principle only shows that doing harm is morally not permissible and that an infringement of personal liberty is allowed in order to prevent harm. The principle, however, does not provide a tool to compare and value conflicting risks of harm nor does it indicate which of the conflicting risks of harm should prevail. To make such a comparison and to decide how to address the conflict, one needs additional arguments.

Second, the aspect of risk illustrates that policies have to deal with the probability that a specific action or type of action results in a harm. The policy is not only about limiting harm, but also about reducing the risk that harm will occur. This is especially relevant, because the policies are not merely focused on the control during an outbreak. Governments also formulate strategies for the prevention of notifiable animal diseases. In those cases, the element of probability plays an even more central role than during an outbreak. This implies that governments do not only have to assess the various types of risk, but also have to assess the risk that harm will occur because of a specific action or practice. In these situations, reference to the harm principle only is not enough to justify government intervention. On the one hand, weighing "risks of harm" confronts policy makers with the aspect of uncertainty. More then once, there is no clear risk, but only a certain probability on certain harm related to a particular action. Simply ignoring or silencing the uncertainty is often no option as the case of the control of BSE or "Mad cow disease" in the UK illustrates. Since 1986, BSE is known as a fatal neurodegenerative disease that affects cattle, but it was only in 1996 that the UK government announced that BSE was linked to a novel human disease that is fatal for humans: the variant Creutzfeldt-Jakob disease (vCJD). Moreover, this disease appeared to be almost certainly caused by consuming BSE-contaminated food. The governmental authorities, however, first were silent about the uncertainty and assured the public that no safety issues were involved in the consumption of beef and that all BSE-related health issues were fully under control. However, at some point the government had to announce that beef consumption could have serious adverse health effects and that they had already known this for some time but had not conveyed the uncertainty they faced. It appeared that the authorities had been erroneously taken the "absence of evidence" as "evidence of absence." (Mepham 2004, p. 331) As a consequence, the UK-government has been severely criticized (House of Lords 2000). This criticism is not so much based upon the knowledge that becomes available after the crisis, but on the way the government ignored dealing with and communicate on the uncertainty they were faced with. Confronted with uncertainty, it is possible to determine what action is preferable, given the available evidence. In these situations extra moral tools, such as the precautionary principle can guide one's decisions.

On the other hand, dealing with the aspect of risk in the claims of stakeholders is more than mere risk calculation. Risk $(R)$ can be defined as the probability $(P)$ of the occurrence of a hazard $(h): R=P \times h$. Therefore, a probability of 0.0001 on the occurrence of a hazard that has a seriousness of 100 leads to the same result as if we are confronted with a hazard with a seriousness of 0.1 and a probability of 0.1 . However, if the 100-unit hazard implies the death of a whole city and the 0.1-unit 
hazard some extra noise for all citizens of that city, because of a train passing by every $30 \mathrm{~min}$, then the risks are differently valued and the risk of the death of a whole city needs stronger justification than the risk of more noise. Although the calculation results in the same figures, the example illustrates that identifying hazards as risks and the assessment of those risks are not the result of pure and value-free calculation (Jensen and Sandøe 2002; Rasmussen and Jensen 2005). Every identification of a hazard as a risk is based upon value-laden assumptions, and moral decisions always (implicitly) play a role in the weighing of risks. This is no different with respect to the control of animal diseases (cf. Anthony 2004; Jensen 2004). In this process the harm principle can be action guiding, because it says to choose that option that preserve most freedom. However, it cannot be the only tool, because of the above-mentioned silence on how to evaluate and weigh different types and amounts of harm. For instance, in their study on the avian influenza virus in The Netherlands in 2003, Bavinck et al. (2009) conclude that "the probability of infection is much smaller for hobby flocks than for commercial farms," but at the same time that "as birds are kept outdoors, backyard flocks may be more at risk for introductions of AI strains (...)." They argue that this can be explained, because "the probability of infection is most likely determined by a complex combination of determinants as the number of animals, the type of species or breeds present, the number and type of contacts between flocks, and the sanitary measures that are put in place." (pp. 252-253).

To decide in such a context, a government needs in addition to the harm principle, value-laden assumptions to deal with both the conflicts and with the risk element of the claims of harm. Only these value assumptions can help to determine what risk of harm should be addressed, even if it is at the cost of leaving another risk unaddressed. For example, if public health is highly valued, one can argue that addressing risks of harm with respect to human health should always prevail over risks of other kinds of harm. Only based on such additional value-laden assumptions it is possible to evaluate the risk aspect of harm and to make choices between conflicting claims of harm. Given this claim, it appears that governments all over Europe make such evaluations and have specific value assumptions. In spite of the shortcomings of the harm principle, they are able to deal with the conflicting risks of harm related to animal disease prevention. This leads us to the conclusion that a focus on these basic assumptions is necessary to understand the criticism of the keepers of backyard animals on the animal disease policy. Before going into the details of the currently used value assumptions, we shortly focus on the criticism from the keepers of backyard animals on the animal disease policy.

\section{The Criticism of Keepers of Backyard Animals}

Keepers of backyard animals are no strict opponents of animal disease policy. However, most of them were very critical of the policy and interventions during the last outbreaks, especially of the lack of differentiation between the different groups of animal keepers (cf. Beekman et al. 2007; Treep et al. 2004). A short analysis of their problems with the methods of prevention and control at the time of the 
outbreaks is helpful in illustrating the shortcomings of the harm principle and in explicating the additional value-lade assumptions used in the current policies.

First, keepers of backyard animals believe they have been wronged by the current policy measures. They consider their hobby as a predominantly private affair (Sijtsema et al. 2005), with its own internal values. The reason to keep animals is part of their idea of the good life. It is not just a hobby; it is part of their lifestyle and an essential element of who they are and what they consider worthwhile in life. In other words, keeping animals is important to their identity. Therefore, policy measures that entail the risk of the culling of animals do not only jeopardize the lives of the animals themselves, or the interests of a certain animal practice, but are considered a serious infringement of one's way of life. They believe that animal disease policy directly interferes with one of their most important freedoms, i.e., to choose one's own life plan that fits one's identity. Apparently, the government evaluated this infringement of freedom as less important than the harm to the public at stake, but this evaluation does not directly follow from the harm principle.

Second, keepers of backyard animals also believe they have been wronged, because they believe that the current policy underestimates the public goods related to their way of keeping animals. They consider the policy measures to signal disrespect with regard to public interests that are promoted by keeping animals for reasons of hobby. It is emphasized that the keeping of animals for recreational purposes results in goods of which its value goes beyond the private level. For instance, the breeding of rare or endangered species is considered as such a good. Also those forms of amateur livestock keeping that represents a type of rural life that has almost disappeared as a result of processes such as the systematic increase of scale in agriculture, urbanization, and industrialization, contribute to goods that are highly valued by the public. Nonetheless, these public goods were, up until recently, not enough reason to provide the keepers of backyard animals a more protected position in the policy. Again, this illustrates the use of additional assumptions next to the harm principle.

Third, these animal keepers claim that the current regulation is far too stringent or even disproportionate, because they believe that they play no role in the outbreak.

Fourth, keepers of backyard animals argue that they are forced to take measures that they do not only consider as too stringent, but also morally unacceptable. For instance, they experience the obligation to keep the animals inside under very harsh restriction as too stringent, but also as morally problematic given the animal welfare consequences.

On top of this, the culling of healthy animals is considered as morally unacceptable. The moral concerns did not only cover moral unease with the killing of animals as such. They believe that perfectly healthy animals are killed purposelessly ${ }^{4}$ and that they were forced to act in a morally objectionable way that leaves them with the idea that they betrayed their animals. ${ }^{5}$ At the last two points,

\footnotetext{
${ }^{4}$ Note that the evaluation of the killing as purposeless is the result of a different evaluation of the risks involved with the other options for action.

${ }^{5}$ This is based upon the results of 24 in-depth interviews that have been held with representatives of organizations for keepers of backyard animals by Cohen as part of the research project "New foundations for prevention and control of notifiable animal diseases."
} 
the additional moral assumptions become most explicit. The problem is not a discussion on the rightful interpretation of the harm principle, but on arguments and values that are used to assess the harms at stake and to evaluate "our willingness, as a society, to bear the harms."

In summary, keepers of backyard animals consider themselves to have been wronged not because they do not agree with the importance of the harm principle, but because they do not agree with the way the possible harms are valued, how the risk element of harm is assessed, and how the conflicts of harms are addressed. It is clear that the criticism of keepers of backyard animals on governmental intervention is not on the harm principle as such. It is much more the result of people's feeling of being wronged by the intervention, because they do not share the underlying moral assumptions and evaluations that result in addressing some risk of harm, while leaving others unaddressed. More in general, keepers of backyard animals do not feel to be taken seriously as stakeholders with interests that are worthwhile protecting and with animals with which they have a special relationship. To understand this criticism, we have to focus on the value assumptions that underlie the current policy.

\section{The Central Role of Value Assumptions and the Problem of an "Economy Only" View}

The justification of the government intervention as part of animal disease policy often implicitly includes a trade off of freedom against other values. In practice, especially economic and veterinary considerations play a crucial role. This bias can easily be understood by the history of animal husbandry in Europe, which has been developed to ensure "food security," i.e., to secure the production of safe food for all, policy, market structures, and technologies aim to increase food production and facilitate free trade. Consequently, this focus can be recognized in the animal disease policies too. There is a clear tendency to assess animal diseases and its consequences in economic terms only. For instance, the decision of the European Union to adopt the former non-vaccination policy was informed by veterinarian arguments, but mainly justified on economic grounds. It was calculated that the economic costs of preventive vaccination were higher than the costs involved with controlling an epidemic. Furthermore, it was argued that a non-vaccination policy stimulates free market trade of animal products between countries, who have adopted this policy (cf. KNAW/Royal Academy of Sciences 2002). This illustrates that the animal disease policy has been mainly focused on economic trade and has evaluated the value of goods merely in terms of its economic benefits.

The current economy-based policies (cf. Dijkhuizen and Morris 1997), however, have become subject to serious criticism. On economic arguments, it has been stressed that it is highly questionable whether this policy strategy is the most cost efficient. For instance, the outbreak of classical swine fever in 1997 was extremely costly for all involved partners. The Dutch government had to compensate farmers, but in spite of the compensation the farmers were financially harmed, and the national and international reputation of the Dutch pig farmers was negatively 
affected. This illustrates that in the long run, it is not so certain whether this policy is sound in economic terms. Another example is the criticism of the calculations that underlie the stamping-out strategy during the 2001-foot and mouth disease. This has been criticized, because the policy turned out to have a serious impact on the tourist industry too. This was not part of the original risk-benefit calculation. A similar claim can be made with respect to the socio-psychological damages to the involved stakeholders entailed by the stamping-out policy that have been ignored in the calculation. On top of this, the recent outbreaks provided a lot of relevant epidemic knowledge that shows some risk calculation to be flawed and some measures to be less relevant than they were expected to be.

Nonetheless, the most profound problems are with the economy-based approach itself. The criticism of keepers of backyard animals signals three broader problems with this approach. First, it illustrates a too limited view of whose interests have to be taken into consideration and who should be seen as a stakeholder who may run a risk of harm as a result of policy intervention. The emphasis on trade and export entails that stakeholder interests are only valued and taken into account as far as they can be assessed within an economic framework. The interests of stakeholders that do not easily fit within this framework are often left out of consideration or only play a marginal role. As a result, the role that non-commercial animal keepers play is very modest. From the perspective of trade, their interests and claims are often subservient to those of the livestock sector that trade and export animals and animal products.

A second point of criticism concerns the overall aim that underlies the evaluation of harm as a legitimate reason for state intervention. Although all agents are considered to be entitled to be protected by the government against harm, what counts as harm is evaluated from the aim to stimulate free market trade of animal products between countries. As a result, the issues that do not easily fit within an economic framework tend to be left out of consideration in the translation of risks of harm into an economical risk-benefit analysis. For instance, the fact that keeping animals is important to the identity of keepers of backyard animals is difficult to translate into economic sound language or in terms of a contribution to free trade. Consequently, an economy-based approach hardly can deal with the importance of this lifestyle aspect. This is problematic, because the infringement of a person's way of life needs a justification other than the argument that it does not fit in an economic framework. Meaningful actions and views on the good life of citizens who keep animals for reasons of hobby are regulated in a way that is unacceptable for them, because the decisions are based upon economical considerations that they do not share and that do not reckon adequately with the lifestyle element that is violated. This problem also holds for the above-mentioned public interests that are related to keeping backyard animals for reasons of the breeding of rare breeds or endangered species. Not all of these goods may contribute to food production or to export, but they have public value.

Third, the economy-based approach can deal with only a limited number of views of the animal and the human-animal relationship. The animal is mainly conceived as a commodity. Consequently, the relationship between human and animal are primarily defined in terms of commodity and owner. From this perspective, the 
animal has a value as far as it is, or can become part of export and trade. Consequently, policy measures that entail the risk of the culling of animals are acceptable if it guarantees future trade. This view is problematic. On the one hand, because empirical research has shown that the public no longer considers arguments based on economic benefit and export only sufficient to justify the culling of healthy animals or to cause very severe animal welfare problems (Treep et al. 2004, p. 55ff; Noordhuizen-Stassen et al. 2003, pp. 43-44). Animals are now commonly conceived as subjects whose value cannot be reduced to their economical worth. On the other hand, the idea of the human-animal relationship as an ownercommodity relationship does not fit with the relationship keepers of backyard animals have with their animals. They value their animals and the relation with them fundamentally differently. They are owners of the animal, but do not value the animals for financial reasons only. Consequently, the government justifies the culling of animals and other preventive measures on grounds they do not share.

These three problems of a strong emphasis on economic considerations in dealing with conflicting risks of harm show that this strategy may be effective, in the sense that it results in priority rules that one needs to apply the harm principle. However, it disregards the plurality of values and norms in society. It is effective only because it forces us to discuss issues of animal disease control and prevention as merely economic and veterinary problems, while the main problem of those who criticize the policy starts in a moral disagreement about how non-economic considerations should be valued.

\section{Conclusion}

In this article, we first have shown that the current problem of animal disease policy cannot be reduced to a problem of the rightful interpretation of the harm principle. The control of animal disease is a matter of dealing with conflicting claims of "risks of harm" that requires an assessment of the types of harm and the probability that a harm may occur. In this process the harm principle is of less guidance. Additional assumptions are needed in order to justify government interventions.

Second, we have argued that these additional assumptions cannot be reduced to economic terms. It requires an interdisciplinary interaction of science, ethics, and society. This is the lesson that can be learned from the criticism of the keepers of backyard animals. Apparently, the disapproval may seem as the opinion of just a minority group. The above analysis, however, shows that their criticism is linked to a discussion with strong connections to non-economic beliefs and values. The problem is a moral one. The basic assumptions that underlie the preventive measures are not shared by the keepers of backyard animals. If one aims to develop a sustainable animal disease policy, this implies that conflicting claims with respect to risks of harm cannot be settled by translating all claims into economic or even monetary terms. As long as not all stakeholders agree on the moral importance and value of the economy, forcing us to discuss the problems in financial terms does not settle the real problem. Only if the moral assumptions of the current policy are 
explicated and the scope of what counts as relevant for animal disease control is broadened can a more robust animal disease policy be developed.

Therefore, the moral values and principles of all involved have to be taken seriously. Ignoring this moral dimension can only be at the cost of leaving the values and interests of some groups out of consideration without sufficient justification.

Acknowledgment This article is part of the research project entitled "New foundations for prevention and control of notifiable animal diseases" that is funded by The Netherlands Organisation for Scientific Research (NWO). We would like to thank the anonymous reviewers for the Journal of Agricultural and Environmental Ethics for their comments.

Open Access This article is distributed under the terms of the Creative Commons Attribution Noncommercial License which permits any noncommercial use, distribution, and reproduction in any medium, provided the original author(s) and source are credited.

\section{References}

Anthony, R. (2004). Risk communication, value judgments, and the public-policy maker relationship in a climate of public sensitivity toward animals: Revisiting Britain's foot and mouth crisis. Journal of Agricultural and Environmental Ethics, 17(4-5), 363-383.

Bavinck, V., Bouma, A., van Boven, M., Bos, M., Stassen, E., \& Stegeman, A. (2009). The role of backyard flocks in the epidemic of highly pathogenic avian influenza virus (H7N7) in The Netherlands in 2003. Preventive Veterinary Medicine, 88, 247-254.

Beekman, V., de Bakker, H. C. M., \& Graaff, R. P. M. (2007). Ethische aspecten dierziektebestrijdingsbeleid; Een oefening in participatieve multi-criteria analyse. Den Haag: LEI.

Brink, D. (2007). "Mill's moral and political philosophy", Stanford Encyclopedia of Philosophy, http://plato.stanford.edu/entries/mill-moral-political [Accessed 26 May 2008].

Cohen, N. E., van Asseldonk, M. A. P. M., \& Noordhuizen-Stassen, E. N. (2007). Social-ethical issues concerning the control strategy of animal diseases in the European union: An inventory. Agriculture and Human Values, 24(4), 499-510.

den Boer, M., Cante, L., Dekker, A., Dyvesteyn, B., Geveke, H., Jansen, R., et al. (2004). De crisis tussen mens en dier, evaluatie bestrijding AI crisis. Utrecht: Berenschot Groep.

Dijkhuizen, A. A., \& Morris, R. S. (1997). Animal health economics: Principles and applications. Sydney, Australia: Post Graduate Foundation in Veterinary Science, University of Sydney.

Feinberg, J. (1984). The moral limits of the criminal law, Vol. 1: Harm to others. Oxford: Oxford University Press.

Feinberg, J. (1994). Freedom and Fulfillment. Princeton: Princeton University Press.

Harcourt, B. E. (1999). The collapse of the harm principle. The Journal of Criminal Law and Criminology, 90(1), 109-194.

Hart, H. L. A. (1961). The concept of law. Oxford: Clarendon Oxford University Press.

House of Lords (2000), Select Committee appointed to consider Science and Technology, Science and Technology-Third Report, 23 Feb 2000, http://www.parliament.the-stationery-office.co.uk/pa/ ld199900/ldselect/ldsctech/38/3801.htm [Accessed at 20 Aug 2008].

Jensen, K. K. (2004). BSE in the UK: Why the risk communication strategy failed. Journal of Agricultural and Environmental Ethics, 17(4-5), 405-423.

Jensen, K. K., \& Sandøe, P. (2002). Food safety and ethics: The interplay between science and values. Journal of Agricultural and Environmental Ethics, 15(3), 245-253.

KNAW/Royal Academy of Sciences. (2002). Bestrijding van mond-en klauwzeer, 'stamping out' of gebruik maken van wetenschappelijk onderzoek. Amsterdam: Koninklijke Nederlandse Akademie van Wetenschappen.

Mepham, B. (2004). Farm animal diseases in context. Journal of Agricultural and Environmental Ethics, 17(4-5), 331-340. 
Mill, J. S. (1859/1979). On liberty, Edited with an introduction by Gertrude Himmelfarb. Harmondsworth, London: Penguin Books.

Noordhuizen-Stassen, E. N., Rutgers, L. J. E., \& Swabe, J. M. (2003). Het doden van gehouden dieren, ja mits...of nee tenzij. Utrecht: Utrecht University.

Rasmussen, B., and Jensen, K. K. (2005). The hidden values. Transparency in decision-making processes dealing with hazardous activities, CeBRA Project Report 5. Copenhagen: Schultz.

Sijtsema, S., van der Kroon, S., van Wijk-Jansen, E., van Dijk, M., Tacken, G., \& de Vos, B. (2005). De kloof tussen de hobbydierhouders en overheid; over passie voor dieren en perceptie van wet-en regelgeving die voor landbouwhuisdieren gelden. The Hague: LEI.

Stegeman, A., Elbers, A., de Smit, H., Moser, H., Smak, J., \& Pluimers, F. (2000). The 1997-1998 epidemic of classical swine fever in The Netherlands. Veterinary Microbiology, 73(2-3), 183-196.

Treep, L., Brandwijk, T., Olink, J., Tillie, F., Veer, M., \& Verhoek, A. (2004). Verkenning hobbydierhouderij, Expertisecentrum LNV, nr. 255. The Hague: EC-LNV.

Van Velzen, K., \& Dekker, I. (2003). Niet ruimen, maar prikken! Hoe Nederland opnieuw massaal gezonde dieren liet afmaken, Report Tweede-Kamerfractie SP. The Hague. 